ANALISIS DATA BERKALA DENGAN METODE SEMI AVERAGE UNTUK PREDIKSI PENDAPATAN ATAU KEUNTUNGAN

( STUDI KASUS : PT. ANGKASA JAYA) 


\section{OLEH KELOMPOK 1}

Doktrin Ivan Khalik Waruwu (17190244)

Viona Sera (1719047)

Rizki Nanda Fadilah (17190294)

Aloysius Januar Hilman (17190320)

KELAS 17.3B.01

SEMESTER 3 


\section{Pengertian analisis data berkala}

Analisis data berkala merupakan suatu analisis yang dapat digunakan untuk mengetahui gerak perubahan atau perkembangan nilai suatu variabel sebagai akibat dari perubahan waktu. Misalkan dalam analisis ekonomi dan lingkungan bisnis biasanya analisis data berkala digunakan untuk meramal (forecasting ) nilai suatu variabel pada masa lalu dan masa yang akan datang berdasarkan pada kecenderungan dari perubahan nilai variabel tersebut.

Analisis data berkala juga merupakan suatu analisis yang berdasarkan hasil ramalan yang disusun atas pola hubungan antara variabel yang dicari dengan variabel waktu yang mempengaruhinya. Pendugaan masa depan dilakukan berdasarkan nilai masa lalu dari suatu variabel.

Analisa deret berkala bertujuan untuk:

1. Mengetahui kecenderungan nilai suatu variabel dari waktu ke waktu.

2. Meramal (forecast) nilai suatu variabel pada suatu waktu tertentu.

\section{Komponen data berkala}

Trend, yaitu gerakan yang berjangka panjang yang menunjukkan adanya kecenderungan menuju ke satu arah kenaikan dan penurunan secara keseluruhan dan bertahan dalam jangka waktu yang digunakan sebagai ukuran adalah 10 tahun keatas.

> Variasi Musim, yaitu ayunan sekitar trend yang bersifat musiman serta kurang lebih teratur.

$>$ Variasi Siklus, yaitu ayunan trend yang berjangka lebih panjang dan agak lebih teratur.

$>$ Variasi Yang Tidak Tetap (Irreguler), yaitu gerakan yang tidak teratur sama sekali. 


\section{Ciri Trend Sekuler}

Trend (T) atau Trend Sekuler ialah gerakan dalam deret berkala yang berjangka panjang, lamban dan berkecenderungan menuju ke satu arah, arah menaik atau menurun. Umumnya meliputi gerakan yang lamanya 10 tahun atau lebih.

Trend sekuler dapat disajikan dalam bentuk :

$>$ Persamaan trend, baik persamaan linear maupun persamaan non linear

$>$ Gambar/grafik yang dikenal dengan garis/kurva trend, baik garis lurus maupun garis melengkung.

Trend digunakan dalam melakukan peramalan (forecasting). Metode yang biasanya dipakai, antara lain adalah Metode Semi Average dan Metode Least Square.

\section{Metode Semi Average}

Metode trend semi average dapat digunakan untuk keperluan peramalan dengan membentuk suatu persamaan seperti analisis regresi. Metode ini dapat digunakan dengan jumlah data genap ataupun ganjil. Dalam analisis trend ini unsur subyektifitas mulai dihapuskan karena teknik peramalannya sudah menggunakan perhitungan-perhitungan. 


\section{Langkah Menggunakan Metode Trend Semi Average}

Berikut langkah-langkah dalam mengaplikasikan metode Trend semi Average untuk peramalan:

1. Kelompokkan data menjadi dua kelompok dengan jumlah tahun dan jumlah deret berkala yang sama.

2. Hitung semi total tiap kelompok dengan jalan menjumlahkan nilai deret berkala tiap kelompok.

3. Carilah rata-rata hitung tiap kelompok untuk memperoleh setengah rata-rata (semi average).

4. Untuk menentukan nilai trend linier untuk tahun-tahun tertentu dapat dirumuskan sebagai berikut: $Y=a+b x$.

\section{Contoh bahan penelitian}

Bahan Penelitian yang digunakan adalah contoh data pendapatan di PT Angkasa Jaya Selama kurun waktu 10 tahun, yang disajikan dalam bentuk tabel yang memuat data tahun serta jumlah pemasukan setiap tahunnya.

\begin{tabular}{|c|c|}
\hline Tahun & Pendapatan (Juta) \\
\hline 2010 & 135 \\
\hline 2011 & 137 \\
\hline 2012 & 104 \\
\hline 2013 & 116 \\
\hline 2014 & 127 \\
\hline 2015 & 190 \\
\hline 2016 & 147 \\
\hline 2017 & 156 \\
\hline 2018 & 143 \\
\hline 2019 & 160 \\
\hline
\end{tabular}

Tabel 1. Data pendapatan PT angkasa jaya 


\section{Metode}

Metode penelitian yang digunakan adalah metode perkembangan, yang dimana sesuai dengan analisis data berkala, yang bertujuan untuk mengetahui gerakan perubahan serta perkembangan nilai suatu variabel sebagai akibat dari perubahan waktu.

PEMBATH

\section{Analisis data}

Dari data tabel tersebut diatas dapat diketahui perkembangan naik turun pendapatan selama 10 tahun dalam diagram berikut:

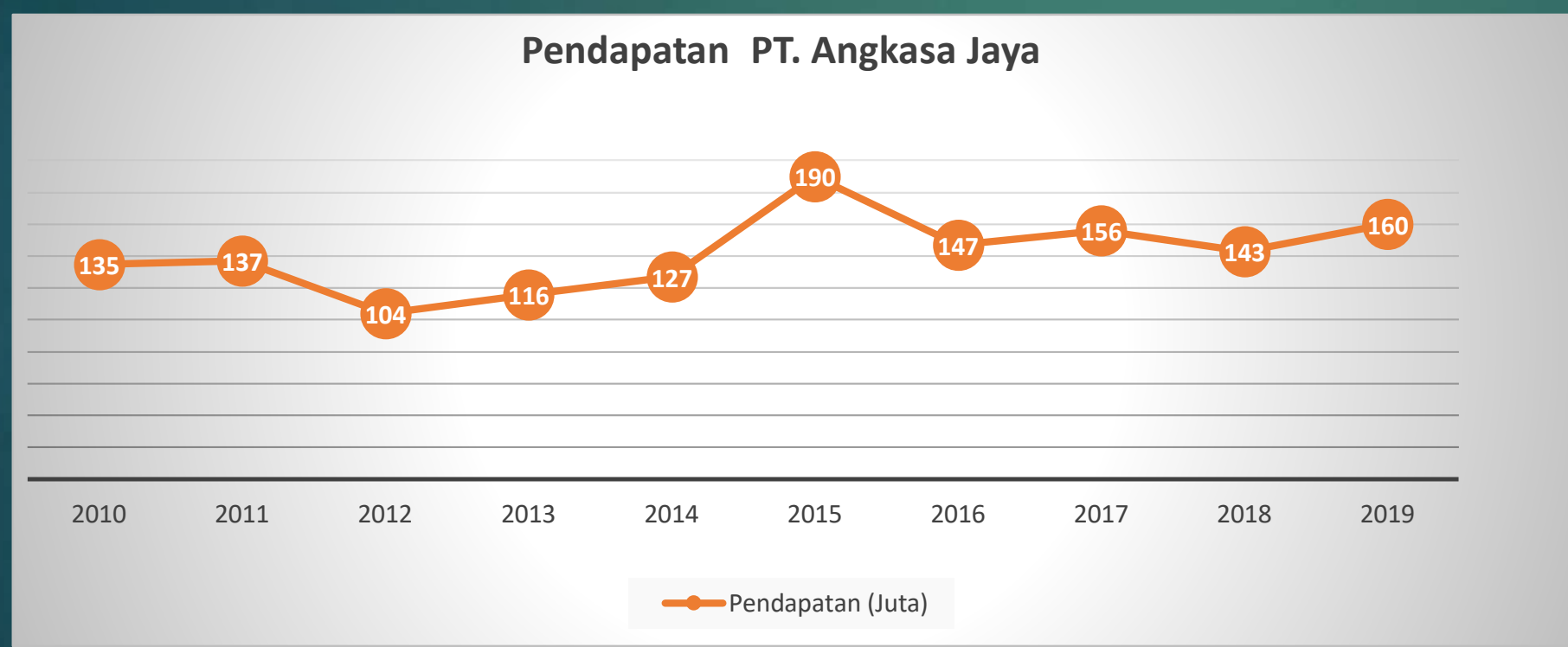

Gambar 1. Diagram pendapatan PT angkasa jaya 


\section{Pembahasan}

Untuk pembahasan akan menggunakan metode data berkala dengan semi average;

a. pertama data di bagi dua kelompok I dan II

b. Tentukan tahun dasar (data tengah masing-masing kelompok) yakni 2014 dan 2017

c. Menghitung semi total :

> Kelompok $\mathrm{I}=135+137+104+116+127=619$

$>$ Kelompok $\mathrm{II}=190+147+156+143+160=796$

d. Menghitung semi average :

Kelompok I : $619 / 5=123,8$

$>$ Kelompok II : 796/5 = 159,2

e. Menentukan Xa (nilai X kelompok I) dengan Nilai 0 di tahun dasar

f. Menentukan $\mathrm{Xb}$ (nilai $\mathrm{X}$ kelompok II) dengan Nilai 0 di tahun dasar

g. Dari formula $Y=a+b X$;

$>$ Menentukan nilai a $=123,8$ atau 159,2 (untuk nilai a, bisa dipilih antara semi average kelompok I atau II)

$>$ Menentukan nilai $\mathrm{b}=(159,2-123,8) / 5$

$$
=7.08
$$




\section{Hasil pembahasan}

Berikut adalah hasil pembahasan yang disajikan dalam bentuk tabel.

\begin{tabular}{|c|c|c|c|c|c|}
\hline Tahun & Pendapatan (Juta) & Semi Total & Semi Average & $X a$ & $\mathbf{X b}$ \\
\hline 2010 & 135 & & & -2 & -7 \\
\hline 2011 & 137 & & & -1 & -6 \\
\hline 2012 & 104 & 619 & 123,8 & 0 & -5 \\
\hline 2013 & 116 & & & 1 & -4 \\
\hline 2014 & 127 & & & 2 & -3 \\
\hline 2015 & 190 & & & 3 & -2 \\
\hline 2016 & 147 & & & 4 & -1 \\
\hline 2017 & 156 & 796 & 159,2 & 5 & 0 \\
\hline 2018 & 143 & & & 6 & 1 \\
\hline 2019 & 160 & & & 7 & 2 \\
\hline
\end{tabular}

Tabel 2. Hasil pembahasan penelitian

$$
\begin{array}{rlrl}
\text { Diperoleh } \mathrm{Y} & =\mathrm{a}+\mathrm{bX} & \text { atau } & \mathrm{Y}=\mathrm{a}+\mathrm{bX} \\
\mathrm{Y}=123,8+7,08 \mathrm{X} & & \mathrm{Y}=159,2+7,08 \mathrm{X}
\end{array}
$$




\section{Peramalan}

Dari hasil pembahasan tersebut, maka dapat dilakukan peramalan untuk jumlah pendapatan pada tahun berikutnya;

Jika kita mencoba misalkan meramal pendapatan untuk tahun berikutnya yaitu 2020, maka:

a. Untuk tahun dasar 2014;

$$
\begin{aligned}
\text { Y } 2020 & =123,8+(7.08 \times 8) \\
& =180,44 \text { Juta }
\end{aligned}
$$

b. Untuk tahun dasar 2017;

$$
\begin{aligned}
\text { Y } 2020 & =159,2+(7,08 \times 3) \\
& =180,44 \text { Juta }
\end{aligned}
$$

\section{Hasil penelitian}

Hasil Penelitian yang didapat dari data pendapatan PT Angkasa Jaya adalah adanya volume naik turun pendapatan selama 10 tahun serta dapat diprediksi pendapatan pada tahun berikutnnya dengan metode peramalan. 


\begin{tabular}{|c|c|}
\hline Tahun & Pendapatan (Juta) \\
\hline 2010 & 135 \\
\hline 2011 & 137 \\
\hline 2012 & 104 \\
\hline 2013 & 116 \\
\hline 2014 & 127 \\
\hline 2015 & 190 \\
\hline 2016 & 147 \\
\hline 2017 & 156 \\
\hline 2018 & 143 \\
\hline 2019 & 160 \\
\hline 2020 & 180,44 \\
\hline
\end{tabular}

Tabel 3. Hasil penelitian pendapatan

1. Langkah-langkah Moving Average Pendapatan Pada Excel
a. Masukkan data berkala (10 tahun pendapatan PT. Angkasa Jaya)
b. Pilih Data pada menu utama
c. Pilih Data Analysis
d. Ketika kotak Analysis Tools, pilih Moving Average 
e. Pada kotak Input Range,sorot pada range B3:B12

$>$ Pada kotak Interval, ketik 3 ( jika tiga periode)

$>$ Pada kotak Output Range, ketik C3

$>$ Berikan tanda check pada Chart Output,

$>$ kemudian $\mathrm{OK}$

\section{Tabel Data Hasil Moving Average Pendapatan Pada Excel}

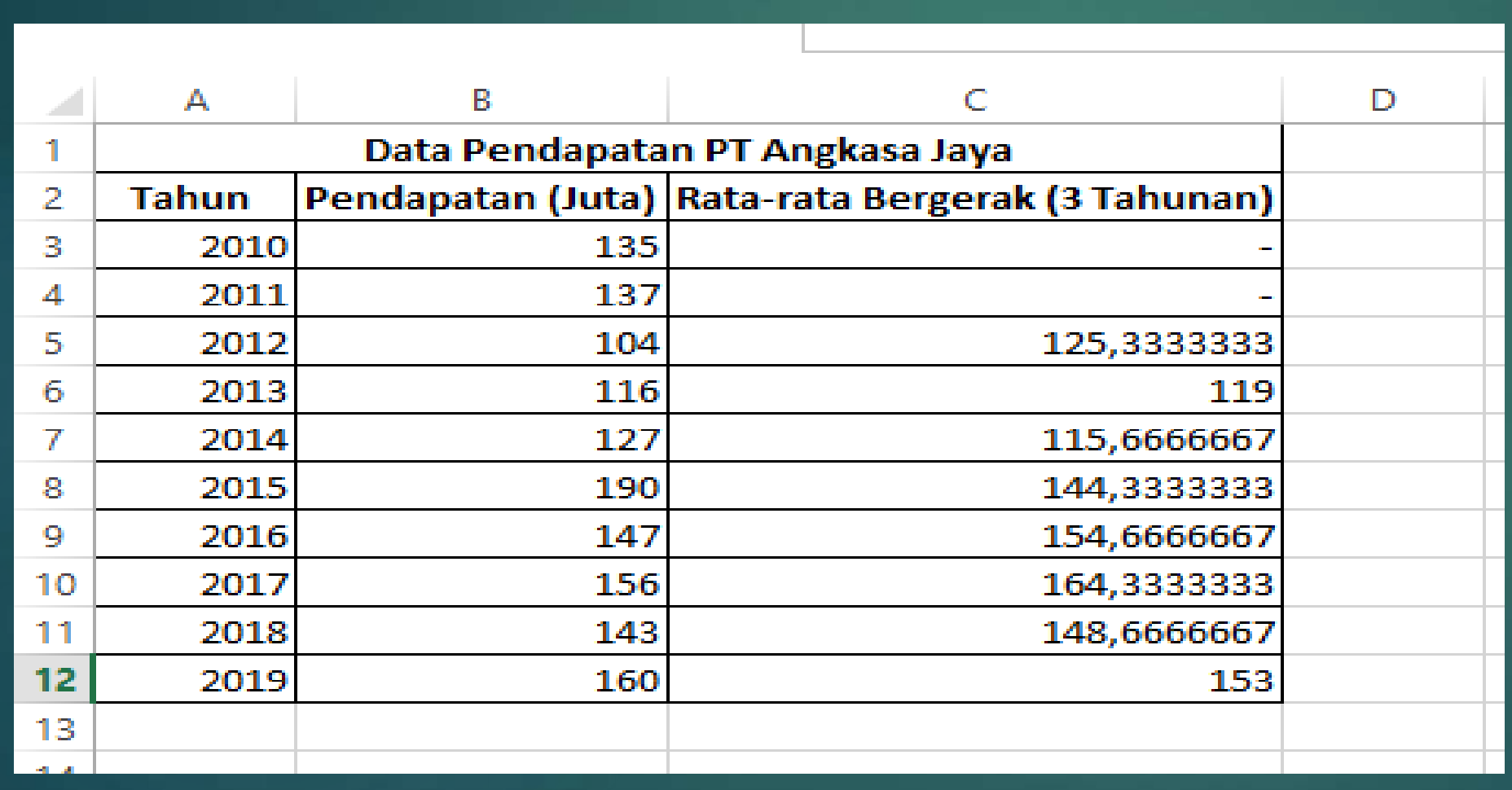

Gambar 2. Tabel data hasil moving average pendapatan pada excel 
3. Diagram Data Hasil Moving Average Pendapatan Pada Excel

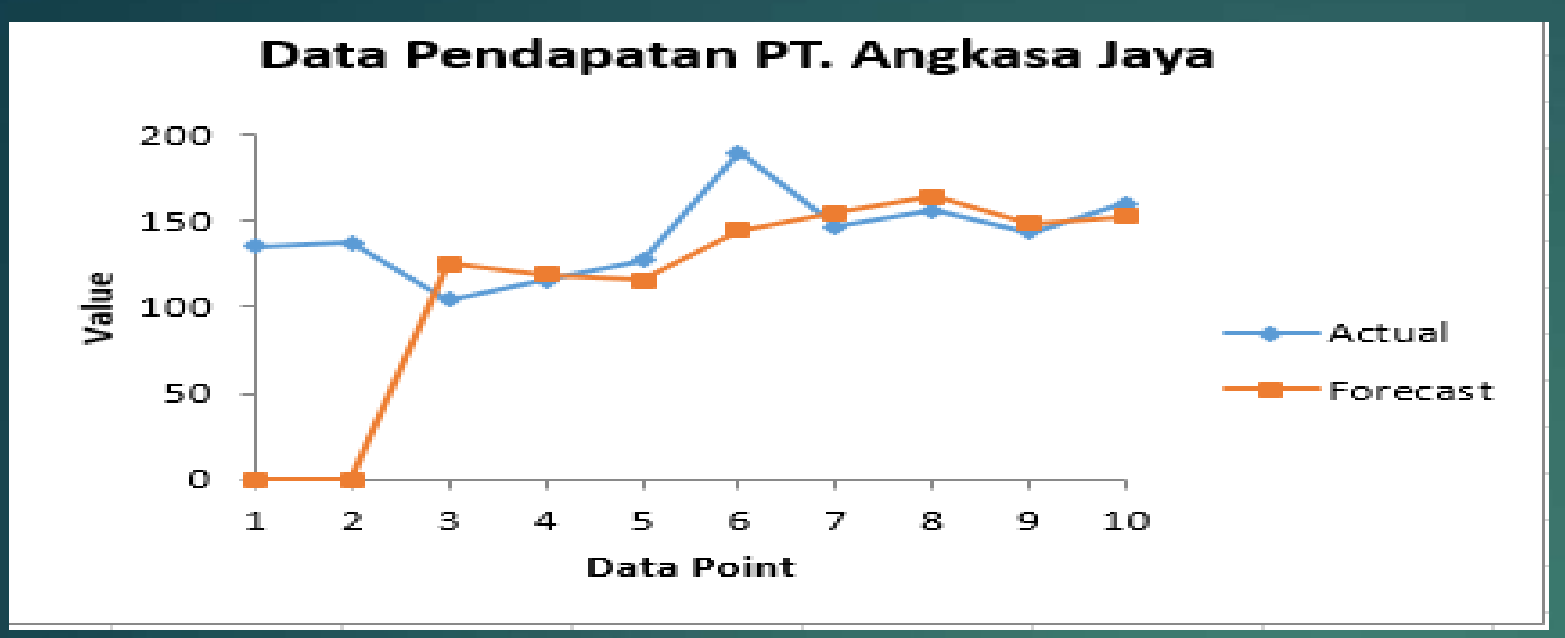

Gambar 3. Diagram data hasil moving average pendapatan pada excel

\section{Langkah-langkah Forecasting Pendapatan Pada Excel}
a. Masukkan data berkala (10 tahun pendapatan PT. Angkasa Jaya)
b. Arahkan kursor ke sel B13
c. Pilih Insert pada menu utama
d. Klik fx
$>$ Pada Or select a category, pilih Statistical
$>$ Pada Select a function, Pilih FORECASH, kemudian klik Ok

Ketika kotak dialog muncul,

$>$ Pada kotak X,ketik 11

$>$ Pada kotak Known_y's, sorot pada range B2:B11

$>$ Pada kotak Known _ X's, sorot pada range A2:A11, kemudian klik OK 


\section{Tabel Data Hasil Forecasting Pendapatan Pada Excel}

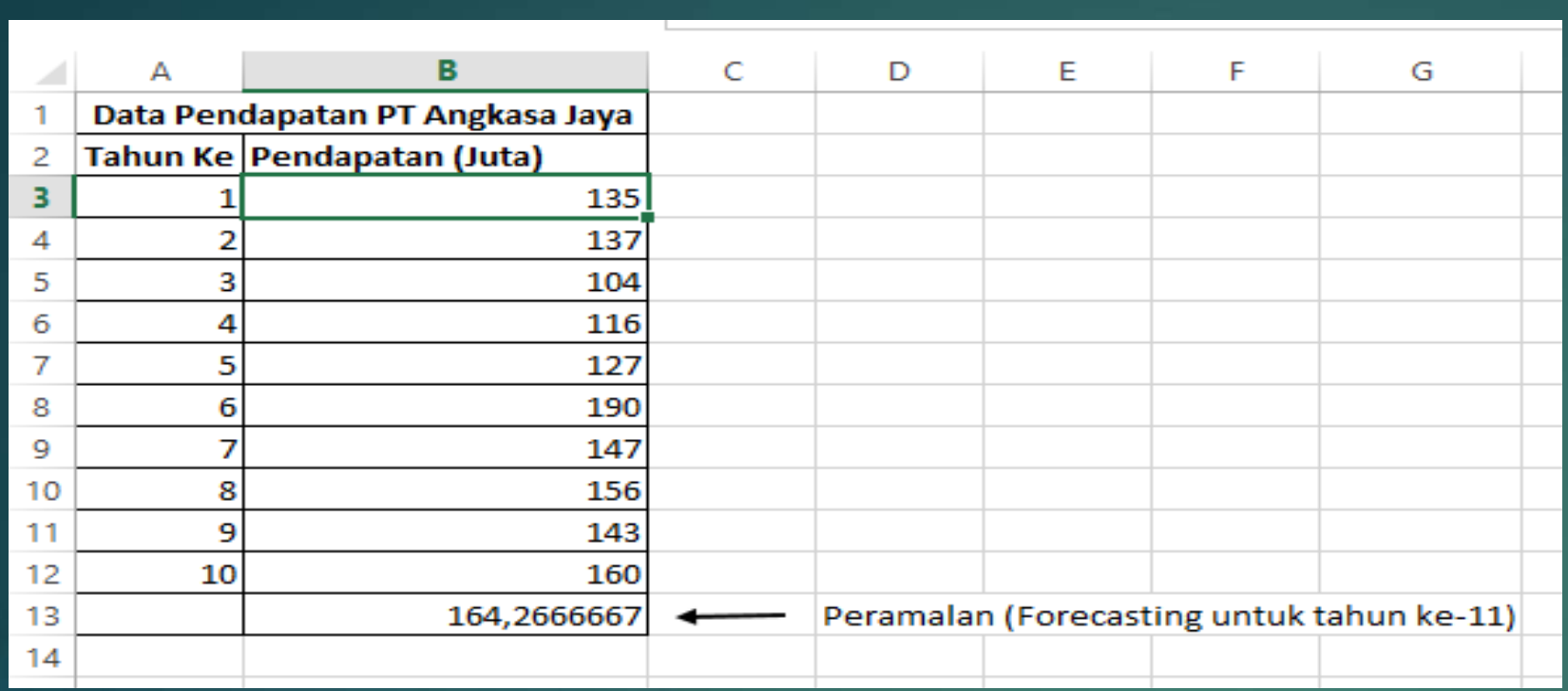

Gambar 4. Tabel data hasil forecasting pendapatan pada excel

6. Langkah-langkah Moving Average Pendapatan Pada SPSS

a. Masukkan data pendapatan PT.Angkasa Jaya.

b. Pada menu Variable view, Masukkan nama THN (tahun ke) dan PNDPTN (pendapatan), kemudian klik Data View. c. Pada menu Data, pilih Define Date And Time. Pada kotak dialog Define Dates, pilih Years kemudian masukkan tahun awal data, klik OK.

d. Pada menu Transform, pilih Create Time Series.

e. Masukkan pendapatan ke kotak Variable. Pada bagian function, pilih Prior Moving Average. Masukkan angka 3(untuk periode tiga tahunan) pada kotak Span, klik Change dan OK. 
7. Tabel Data Hasil Moving Average Pendapatan Pada SPSS

a. Input

\begin{tabular}{|c|c|c|c|c|c|}
\hline & $\&$ THN & $\&$ PNDPTN & $\&$ YEAR & O DATE & $\&$ PNDPTN 1 \\
\hline 1 & 1 & 135 & 2010 & 2010 & \\
\hline 2 & 2 & 137 & 2011 & 2011 & \\
\hline 3 & 3 & 104 & 2012 & 2012 & \\
\hline 4 & 4 & 116 & 2013 & 2013 & 125,3 \\
\hline 5 & 5 & 127 & 2014 & 2014 & 119,0 \\
\hline 6 & 6 & 190 & 2015 & 2015 & 115,7 \\
\hline 7 & 7 & 147 & 2016 & 2016 & 144,3 \\
\hline 8 & 8 & 156 & 2017 & 2017 & 154,7 \\
\hline 9 & 9 & 143 & 2018 & 2018 & 164,3 \\
\hline 10 & 10 & 160 & 2019 & 2019 & 148,7 \\
\hline
\end{tabular}

Gambar 5. Input data hasil pendapatan pada SPSS

b. Output

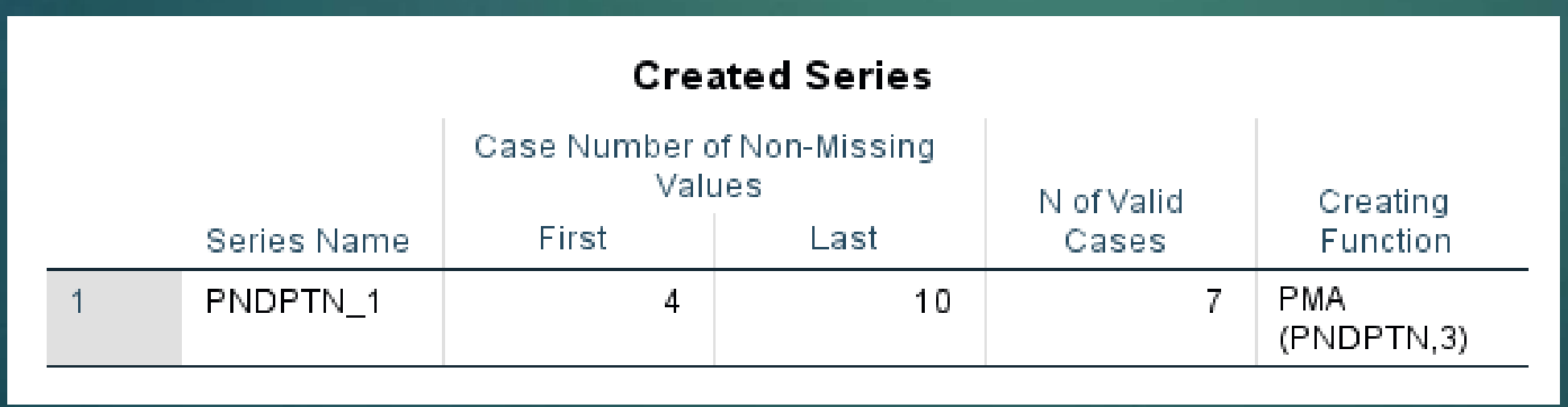

Gambar 6. Output data hasil pendapatan pada SPSS 


\section{Langkah-langkah Forecasting Pendapatan Pada SPSS}

a. Masukkan data pendapatan PT.Angkasa Jaya.

b. Pada menu Analyze, pilih Forecasting, kemudian pilih Create Traditional Models.

c. Kotak dialog Time Series Modeler muncul :

$>$ Pada bagian Variables, masukkan Pendapatan ke kotak Dependent Variables dan Tahun ke pada kotak Independent Variables.

$>$ Pada bagian Statistic, pilih model statistik yang ingin ditampilkan dengan tanda centang, serta beri tanda centang pada Display Forecasts.

$>$ Pada bagian Plots, beri tanda centang pada Plot yang ingin ditampilkan.

$>$ Pada bagian Save, beri tanda centang pada Description yang ingin ditampilkan.

$>$ Pada bagian Options, pilih First case after end of estimation period through a specified date. Kemudian masukkan tahun 2020 (Tahun ke - 11) pada kotak Year.

d. Klik OK.

\section{Data Hasil Forecasting Pendapatan Pada SPSS}

a. Tabel Input Pendapatan

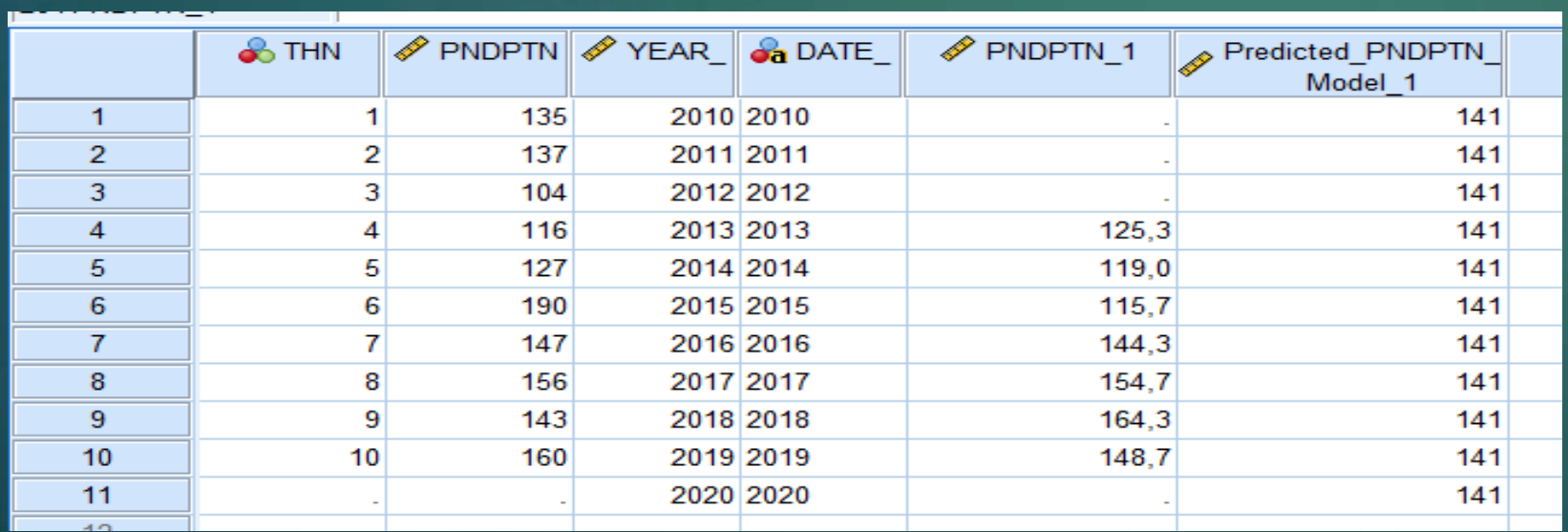

Gambar 7. Tabel input forecasting pendapatan SPSS 


\begin{tabular}{|c|c|c|c|c|c|c|c|c|c|c|c|}
\hline \multicolumn{12}{|c|}{ Model Fit } \\
\hline \multirow[b]{2}{*}{ Fit Statistic } & \multirow[b]{2}{*}{ Mean } & \multirow[b]{2}{*}{ SE } & \multirow[b]{2}{*}{ Minimum } & \multirow[b]{2}{*}{ Maximum } & \multicolumn{7}{|c|}{ Percentile } \\
\hline & & & & & 5 & 10 & 25 & 50 & 75 & 90 & 95 \\
\hline Stationary R-squared & ,000 & & ,000 & ,000 &, 000 & ,000 & ,000 & ,000 & ,000 &, 000 & ,000 \\
\hline R-squared &, 000 & &, 000 &, 000 &, 000 &, 000 &, 000 &, 000 &, 000 &, 000 &, 000 \\
\hline RMSE & 24,190 & & 24,190 & 24,190 & 24,190 & 24,190 & 24,190 & 24,190 & 24,190 & 24,190 & 24,190 \\
\hline MAPE & 12,873 & & 12,873 & 12,873 & 12,873 & 12,873 & 12,873 & 12,873 & 12,873 & 12,873 & 12,873 \\
\hline MaxAPE & 36,058 & & 36,058 & 36,058 & 36,058 & 36,058 & 36,058 & 36,058 & 36,058 & 36,058 & 36,058 \\
\hline MAE & 17,700 & & 17,700 & 17,700 & 17,700 & 17,700 & 17,700 & 17,700 & 17,700 & 17,700 & 17,700 \\
\hline MaxAE & 48,500 & & 48,500 & 48,500 & 48,500 & 48,500 & 48,500 & 48,500 & 48,500 & 48,500 & 48,500 \\
\hline Normalized BIC & 6,602 & & 6,602 & 6,602 & 6,602 & 6,602 & 6,602 & 6,602 & 6,602 & 6,602 & 6,602 \\
\hline
\end{tabular}

Gambar 8. Tabel model fit

c. Tabel Model Statistics

\begin{tabular}{|c|c|c|c|c|c|c|}
\hline \multirow[b]{3}{*}{ Model } & \multicolumn{5}{|c|}{ Model Statistics } & \multirow{3}{*}{$\begin{array}{c}\text { Number of } \\
\text { Outliers }\end{array}$} \\
\hline & \multirow{2}{*}{$\begin{array}{l}\text { Number of } \\
\text { Predictors }\end{array}$} & $\begin{array}{l}\text { Model Fit } \\
\text { statistics }\end{array}$ & \multicolumn{3}{|c|}{ Ljung-Box Q(18) } & \\
\hline & & R-squared & Statistics & DF & Sig. & \\
\hline Pendapatan-Model_1 & 0 &, 000 & & 0 & & 0 \\
\hline
\end{tabular}

Gambar 9. Tabel model statistics 
d. Tabel Forecast

\begin{tabular}{|c|c|c|}
\hline \multicolumn{3}{|c|}{ Forecast } \\
\hline \multicolumn{2}{|l|}{ Model } & 020 \\
\hline \multirow[t]{3}{*}{ Pendapatan-Model_1 } & Forecast & 141 \\
\hline & UCL & 196 \\
\hline & LCL & 87 \\
\hline \multicolumn{3}{|c|}{$\begin{array}{l}\text { For each model, forecasts start after the last } \\
\text { non-missing in the range of the requested } \\
\text { estimation period, and end at the last period } \\
\text { for which non-missing values of all the } \\
\text { predictors are available or at the end date of } \\
\text { the requested forecast period, whichever is } \\
\text { earlier. }\end{array}$} \\
\hline
\end{tabular}

Gambar 10. Tabel forecast

\section{e. Diagram Hasil Forecasting}

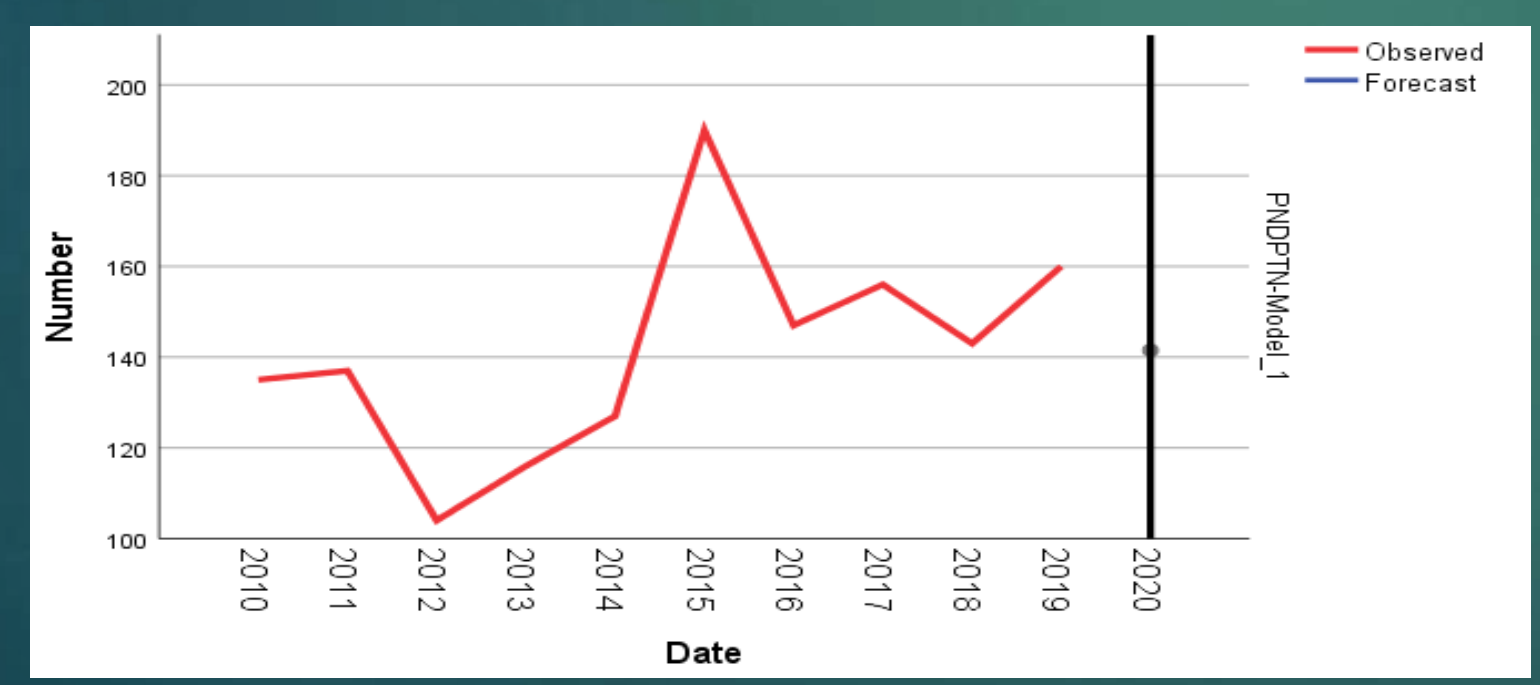

Gambar 11. Diagram hasil forecasting 
1. Metode trend semi average dapat digunakan untuk keperluan peramalan dengan membentuk suatu persamaan seperti analisis regresi.

2. Dari contoh data penelitian tersebut di atas diperoleh:

a. Terjadinya volume naik turun pada pendapatan atau tidak tetap

b. Melalui metode semi average, maka pendapatan untuk tahun berikutnya dapat diprediksi atau di ramalkan. 